Hegemonia - Revista Eletrônica do Programa de Mestrado em Direitos Humanos, Cidadania e Violência/Ciência Política do Centro Universitário Unieuro

ISSN: $1809-1261$

UNIEURO, Brasília, número 26, Janeiro a Junho de 2019, pp. 30-39.

Recebido em: 22/07/2018

Avaliado em: 19/09/2018

Aprovado em: 21/10/2018

\title{
DEMOCRACIA Y DERECHO A LA INTEGRIDAD PERSONAL
}

\author{
Martha Fabiola García-Álvarez ${ }^{1}$
}

Resumen: En la investigación realizada se expone cómo se viola el derecho a la integridad personal en México, con la democracia en decadencia, la cual defiende la soberanía del pueblo con derecho a elegir gobernante, sin embargo se viola la dignidad del mismo, la integridad física y psíquica. El derecho a la igualdad no existe sin libertad, siendo afectados en mexicanos por la criminalidad, que a su vez ésta es susceptible a factores de riesgo que generan conflictos sociales y desestabilizan las garantías individuales y la democracia; resquebrajándose la confianza del pueblo hacia los tres poderes ejecutivo, legislativo y judicial, incrementándose el fenómeno de la "justicia por propia mano".

Palabras claves: Democracia, derecho, integridad personal, factores de riesgo.

Abstract: The investigation shows how the right to personal integrity in Mexico is violated, with democracy in decline, which defends the sovereignty of the people with the right to elect a ruler, however the dignity of the same is violated, physical integrity and psychic The right to equality does not exist without freedom, being affected in Mexicans by criminality, which in turn is susceptible to risk factors that generate social conflicts and destabilize individual guarantees and democracy; the confidence of the people towards the three executive, legislative and judicial powers was broken, increasing the phenomenon of "justice by own hand".

Keywords: Democracy, law, personal integrity, risk factors.

Introducción

La finalidad de exponer este trabajo, es conocer la participación de la criminalidad, los factores de riesgo y consecuencias de la violación de derechos humanos y emergentes, como lo son los de la integridad personal, seguridad humana y pública, a la vida y, afectando a la democracia.

1 Doutora em Ciências Políticas e Sociais, e docente do Centro Universitario de los Altos, Universidad de Guadalajara. 
Artigo original

Hegemonia - Revista Eletrônica do Programa de Mestrado em Direitos Humanos, Cidadania e Violência/Ciência Política do Centro Universitário Unieuro

ISSN: $1809-1261$

UNIEURO, Brasília, número 26, Janeiro a Junho de 2019, pp. 30-39.

Se detecta gran desplazamiento de delincuentes, entre la colonia donde viven a otra, entre Estados y localidades, para cometer delito, modificando la dinámica delictiva, los grados de peligrosidad, planeación, instrumentos utilizados y los cambios en la autoría delictiva; esto conlleva a una mutación y evolución criminal de alto riesgo.

En los reclusorios del Estado de Jalisco, existen problemas a nivel economía, laboral, educación, salud, que generan un costo elevado para el país, que necesitan de manera urgente los programas, convenios y políticas públicas. En este sentido, se debe de tomar en cuenta algunos determinantes de la salud como, la Biología Humana, que es condicionada por la genética y sometida al envejecimiento; el medioambiente, con los contaminantes físico-químicos, psicosociales, culturales, clima; el estilo de vida.

En el CEINJURE Altos Sur, Reclusorio Preventivo de Guadalajara y el Centro Preventivo y de Reinserción Femenil ${ }^{2}$, se identificó la necesidad de que, mediante programas de salud, los internos modifiquen su conducta, de impulsividad, irritabilidad, agresividad, falta de remordimientos, problemas mentales y psicológicos, crueldad, falta de empatía, irresponsabilidad y despreocupación por las normas, falta de control, ansiedad, dificultad de trato con figuras de autoridad, apatía emocional, consumo de drogas y alcohol.

Entre los antecedentes de estos reclusos, son la agresividad e intolerancia hacia las autoridades, la utilización de armas blancas con frecuencia, miembros de pandillas, práctica de la vagancia, su relación con otros delincuentes y el uso de tatuajes.

\footnotetext{
${ }^{2}$ García Álvarez Martha Fabiola, et.al. Datos derivados de los proyectos: Análisis de la Conducta Delictiva Femenina, desde la Perspectiva Socio-Jurídica y Criminológica, en Jalisco. Jalisco, México. Aspecto Socioeconómico como un Factor de Riesgo en las Conductas Delictivas en la Ciudad de Tepatitlán de Morelos, Jalisco. México. Estudio Multidisciplinario de los Problemas Actuales de la Conducta del Delincuente: Estudios de Casos; Análisis Multidisciplinario sobre la Educación como uno de los Problemas de la Conducta Delictiva en México: Estudios de Casos; Proyecto Genético para hacer Estudios de Asociación del Polimorfismo 5HTTLPR del Gen SLCG44 con Personalidady Comportamiento Penitenciario. (2004-2014).
} 
Artigo original

Hegemonia - Revista Eletrônica do Programa de Mestrado em Direitos Humanos, Cidadania e Violência/Ciência Política do Centro Universitário Unieuro

ISSN: $1809-1261$

UNIEURO, Brasília, número 26, Janeiro a Junho de 2019, pp. 30-39.

1. Antecedentes. Diagnóstico de la Problemática.

En la población Mexicana se viola continuamente el derecho a la integridad personal y los que atentan contra la vida, mediante diversos tipos de delitos y mutación de los mismos.

La delincuencia en México no se puede entender sin exponer diversos factores que la generan, entre ellos serían la cultura, la política, la economía y en general las historias de vida de los criminales, quienes durante su vida han estado expuestos a ciertos factores de riesgos, como lo son el medio ambiente social donde se desarrollan, ambiental y climático, la familia, el vivir en zonas marginadas y cinturones de pobreza, la segregación, entre otros.

En el medio social cada vez se desvincula el ser humano de los valores universales, teniendo mayor insensibilidad y falta de empatía al sufrimiento ajeno por parte de quien comete delito, y esto no es exclusive al hombre, la mujer también actúa de esta manera.

Otro de los fenómenos que se están dando cada vez más, es el hecho de que en los centros urbanos del país, se detectan cada vez más desplazamientos de personas que se dedican a cometer ilícitos, van de colonias a otras, igualmente a otros Estados de la República Mexicana, muchas de las veces como primer objetivo la búsqueda de oportunidades, sin embargo, el mismo medio y las personas que van conociendo durante este trayecto, las van envolviendo en la vida delictiva.

\section{Metodología.}

Se realizó trabajo de campo mediante entrevistas a hombres y mujeres recluidos por el delito de homicidio en el Reclusorio Preventivo de Guadalajara y el Centro Preventivo y de Readaptación Femenil de Puente Grande, Jalisco (2013-2014). 
Artigo original

Hegemonia - Revista Eletrônica do Programa de Mestrado em Direitos Humanos, Cidadania e Violência/Ciência Política do Centro Universitário Unieuro

ISSN: 1809-1261

UNIEURO, Brasília, número 26, Janeiro a Junho de 2019, pp. 30-39.

Métodos utilizados para obtener la población, las muestras. Utilizándose métodos de investigación de la Criminología, Derecho y Sociología, debido a los diferentes aspectos relacionados con la delincuencia y la justicia que necesitan investigarse desde un punto de vista sociológico, de observación directa, indirecta y sistemática con base en preguntas de carácter empírico, en interacción mediante observación, entrevistas con estudios de casos e historias de vida de las recluidas; en qué creencias y normas se rigen, y se complementa con las observaciones en campo, con otro tipo de material escrito en referencia al problema a tratar. De igual importancia, resulta el método de estudios de casos, que significa la muestra que se estudió.

\section{Discusión y resultados.}

Los resultados arrojaron que el 95\% de esta población penitenciaria han tenido en su historia de vida factores de riesgo que los indujo a cometer una serie de delitos mixtos, incluidos los que atentan contra la vida e integridad personal.

La sociedad al verse afectada por la ola de delincuencia y, de acuerdo a su percepción, desconfían de las instituciones de seguridad pública y las que imparten justicia. Esta inseguridad en que vive diariamente dicha sociedad, ha generado un fenómeno cada vez más presente en colonias y poblados de nuestro país, este es el de la "Justicia por su propia mano".

Existen otros factores que influyen en la conducta delictiva, como lo son el cultural, la pobreza, los cambios y desorganización social. En toda conducta está presente la violencia, lo cual genera agresividad y una falta de control en las acciones que lleva a cabo la persona que comete delito, comenzando con el consumo de drogas y alcohol, lo cual es consecuencia o causa de conflictos interpersonales.

El auge y evolución de ciertos delitos que van mutando, así como cambios en la criminodinámica, incrementando los grados de peligrosidad, hasta llegar a convertirse en un criminal de alto riesgo. 
Artigo original

Hegemonia - Revista Eletrônica do Programa de Mestrado em Direitos Humanos, Cidadania e Violência/Ciência Política do Centro Universitário Unieuro

ISSN: $1809-1261$

UNIEURO, Brasília, número 26, Janeiro a Junho de 2019, pp. 30-39.

Otra de las características de quienes cometen delito, es la falta de adaptación al medio que les rodea, buscando donde sentirse más cómodo y sobre todo aceptados, asimismo, tienen una excesiva reacción ante la frustración, así que generan mecanismos de defensa para protegerse de cualquier afectación; y precisamente por esta forma de actuar son fácilmente influenciables, especialmente las mujeres, poseyendo una gran pobreza afectiva.

Del mismo modo, este tipo de personas desean tener continuamente el control y poder, así como tienden a las conductas autodestructivas. Generalmente los delincuentes tienen una historia de vida con experiencias traumáticas, en donde en el medio en que se desarrollan siguen su propio código de conducta para poder sobrevivir y no desaparecer como persona.

Continuando con la historia de vida de los entrevistados, se identificó que en un porcentaje alto tienen el nivel de escolaridad de medio a bajo, viviendo en un cinturón de pobreza, en espacios pequeños, con poca recreación, y donde la familia disgregada compiten entre sí laboralmente para sobrevivir y esto fractura la familia peligrosamente.

Otro de los fenómenos actuales que suceden en México con relación a la violencia y percepción de la inseguridad es que calles, colonias y hasta poblaciones completas están tan acostumbradas a la inseguridad y violencia, que es algo "normal", y prefieren obtener justicia por su propia mano, es "ojo por ojo, diente por diente". En estos espacios los criminales secuestran, matan, roban, etc., siendo decisión propia de los habitantes (80\%) no hacer denuncias, y que la policía no haga su trabajo de poner orden en la zona.

En la historia de vida de los delincuentes, está impregnada de agresividad e intolerancia hacia las autoridades, utilizan armas blancas con frecuencia, llegan a ser miembros de pandillas, practican la vagancia, se relacionan con otros delincuentes y con frecuencia usan tatuajes.

Las zonas habitacionales, de diversión y recreación se están disminuyendo cada vez más en razón del espacio, por lo tanto la falta de éstos, tienen una significativa influencia en la conducta. 
Hegemonia - Revista Eletrônica do Programa de Mestrado em Direitos Humanos, Cidadania e Violência/Ciência Política do Centro Universitário Unieuro

ISSN: 1809-1261

UNIEURO, Brasília, número 26, Janeiro a Junho de 2019, pp. 30-39.

A partir de estas condiciones, las mujeres son más vulnerables a la explotación humana, ejemplo de ello es la infantil, a delitos como la trata de blancas, pornografía, prostitución, tráfico de órganos, etc.

Los delincuentes en la generalidad son seres marginados sociales quienes padecen todo tipo de consecuencias como la hambruna, baja o nula educación, pérdida de valores universales, integración en grupos delictivos, promiscuidad, desintegración familiar, salud, abandono, en especial lo sufren los niños, además de víctimas de delitos.

En este sentido, es importante analizar las reacciones de la sociedad ante la conducta de las mujeres, desde la niñez hasta la actualidad, en el entorno en que han vivido, a las actividades que se dedican y todo el contexto en que se desarrollan, es que desde pequeñas se les ha violado varias de las garantías y derechos, comenzando con la libertad y la igualdad.

Un punto clave es el hecho de que se violenta la integridad personal de la mujer homicida, comenzamos con el Principio de seguridad humana que se relaciona con el Principio de género, que defiende los derechos de las mujeres y la no discriminación, así como la diversidad sexual y la dimensión de género desde la masculinidad.

Se identifica que en las mujeres no existe igualdad de derechos, por lo tanto tampoco libertad, como ejemplo con las homicidas entrevistadas en el Centro Preventivo y de Readaptación Femenil de Puente Grande, Jalisco, ya que la vida que les ha tocado vivir carece de calidad y dignidad.

Se establece que esta dignidad no la poseen las reclusas desde antes de ingresar al reclusorio, pues no deciden sobre su propia vida, la mayoría no escogió cómo y dónde vivir, fue impuesto 
Artigo original

Hegemonia - Revista Eletrônica do Programa de Mestrado em Direitos Humanos, Cidadania e Violência/Ciência Política do Centro Universitário Unieuro

ISSN: 1809-1261

UNIEURO, Brasília, número 26, Janeiro a Junho de 2019, pp. 30-39.

y/o necesario. Todo este contexto desencadenó una conducta de autodestrucción y miseria, conllevándola a cometer delitos, consumo de drogas y alcohol, prostituirse.

Parte de la violencia de la que han sido objeto estas mujeres, es que la misma que les arrebató la dignidad, igualdad y libertad. Esta violencia genera más violencia que va en crecimiento, construyendo desarmonía y descontrol en el sistema social, formado por la familia, autoridades judiciales, sociedad, etc., en donde el resultado es la formación de conductas desintegradoras y destructivas.

De esta manera, dignidad, igualdad y libertad, constituyen el derecho a la integridad personal, el cual en toda persona debe de ser inviolable, con derechos a su integridad física y psíquica. Esta protección hacia la mujer ha fallado desde su niñez y durante toda su juventud, no comienza en su reclusión por el delito que cometió.

Es por ello, en la investigación realizada sobre las homicidas, es importante conocer la historia de vida y cómo, dónde, con quiénes se generó este tipo de conducta, es decir, se buscan las razones por las cuales la homicida cometió su delito y todos los aspectos internos y externos que influyeron en su conducta.

\section{Conclusiones}

El derecho a la integridad personal y la democracia van de la mano, violándose éstos mediante diversos tipos de delitos ha llevado a generarse el fenómeno de la justicia por propia mano, en donde la participación de criminales conlleva al análisis de los factores de riesgo y estimulantes a los que son expuestos quienes violan los derechos humanos y emergentes, como lo son el medio ambiente en que se desarrollan, el consumo de estupefacientes, la familia.

Los actos violentos ejercidos por homicidas provienen de una combinación de aspectos multifactoriales, además del cambio de rol de víctima a victimaria, en un 90\% de los casos de las 
Artigo original

Hegemonia - Revista Eletrônica do Programa de Mestrado em Direitos Humanos, Cidadania e Violência/Ciência Política do Centro Universitário Unieuro

ISSN: 1809-1261

UNIEURO, Brasília, número 26, Janeiro a Junho de 2019, pp. 30-39.

mujeres, que trae consigo problemas psicológicos y sociales en la conducta de homicidas; sumándose en algunas de ellas las enfermedades mentales y con alto grado de agresividad. Esta y otras condiciones de riesgo, les lleva a involucrarse en conductas antisociales y/o delictivas con mayor facilidad.

Existe una influencia significativa del medioambiente en la conducta de quien comete delito, con los contaminantes físico-químicos, psicosociales, culturales, clima; el estilo de vida, con un gran incremento de la pobreza, sin saber que sean biológica y ecológicamente sostenibles. Además, la contaminación visual, auditiva y olfativa llega a modificar la conducta del ser humano significativamente.

Bibliografía

Aguilar, Adrián Guillermo; Escamilla H., Irma (2015) Segregación Urbana y Espacios de Exclusión. Ejemplos de México y América Latina, Editorial MAPorrúa Librero Editor México.

Asamblea General de las Naciones Unidas

Comisión de los Derechos Humanos de las Naciones Unidas

Constitución Política de los Estados Unidos Mexicanos

Davis, Mike (2014) Planeta de ciudades miseria, Ediciones Akal, S.A., Madrid, España.

Declaración de los Derechos Humanos

Declaración de los Derechos Humanos Emergentes, https://www.idhc.org/es/investigacion/publicaciones/derechos-humanosemergentes/declaracion-universal-de-derechos-humanos-emergentes.php

Diario Oficial de la Federación (1986).

Diccionario Jurídico Mexicano, Instituto de Investigaciones Jurídicas, editorial Porrúa, Unam (2001).

García Álvarez, Martha F., (2013-2014) Estudio Multidisciplinario de los Problemas Actuales de la Conducta del Delincuente, Estudios de Casos. Análisis Multidisciplinario sobre la Educación como uno de los 
Artigo original

Hegemonia - Revista Eletrônica do Programa de Mestrado em Direitos Humanos, Cidadania e Violência/Ciência Política do Centro Universitário Unieuro

ISSN: $1809-1261$

UNIEURO, Brasília, número 26, Janeiro a Junho de 2019, pp. 30-39.

Problemas de la Conducta Delictiva en México: Estudios de Casos; y Asociación del Polimorfismo 5HTTLPR del Gen SLCG44 con Personalidady Comportamiento Penitenciario (Autor del proyecto: Dra. Valeria Peralta. Desarrollo y conclusión del Proyecto sin muestras de sangre: Dra. Martha Fabiola García A.). Proyectos de Investigación no publicados, Sociedad Mexicana de Criminología capítulo Nuevo León, A.C. Puente Grande, Jalisco. Proyectos de Investigación.

------------ (2011) Análisis de la Conducta Delictiva Femenina, desde la Perspectiva Socio-Jurídica y

Criminológica, en Jalisco. Jalisco, México. Tesis de Doctorado. - (2004) El Aspecto Socioeconómico como un Factor de Riesgo en las Conductas Delictivas en la Ciudad de Tepatitlán de Morelos, Jalisco. México. Tesis Maestría.

González de la Vega, René, (2001) Políticas Públicas en Materia de Criminalidad. Teoría de los Escenarios 2000-2030, Editorial Porrúa, México.

Lewis, O., (1961), The Children of Sancher. Autobiography of a Mexican Family, Nueva York.

Pezzoli, K., (1998), Human Settlements and Planning for Ecological Sustainability. The Case of Mexico City, Cambridge, p. 13.

Proyect Counseling Services, (diciembre 2002), Deteriorating Bogotá. Displacement and War in Urban Centres, Columbia Regional Report, Bogotá, pp. 3-4.

Rwezaura, B., (2003), et al., citado por M. Grant, Dificult Debut. Social and Economic Identities of Urban Youth in Bulawayo, Zimbabwe, Canadian Journal of African Studies XXXVII, 2/3, pp. 416-417. Seabrook, J., (1996), In the Cities of the South, Londres, p. 197

UN-Habitat, (2003), Slums of de World, The Face of Urban Poverty in the New Milenium?, documento de trabajo, Nairobi, Anexo 3.

Zanetta, C., (2004), The Influence of the World Bank on National Housing Policies, p. 64. 